\title{
Fitting in: Different Types of Person-Environment Fit as Drivers of Career Self-management in Kuwait
}

\author{
Ikhlas Abdalla ${ }^{1}$, Awad M. Al-Zufairi ${ }^{1}$, Moudi Al-Homoud ${ }^{1} \&$ Ali H. Muhammad ${ }^{1}$ \\ ${ }^{1}$ Department of Management and Marketing, College of Business Administration, Kuwait University, Kuwait \\ Correspondence: Ikhlas Abdalla, Department of Management and Marketing, College of Business \\ Administration, Kuwait University, Kuwait.
}

Received: July 22, 2019

doi:10.5539/ibr.v12n9p29

\author{
Accepted: August 16, $2019 \quad$ Online Published: August 26, 2019 \\ URL: https://doi.org/10.5539/ibr.v12n9p29
}

\begin{abstract}
Contributing to emerging efforts to integrate the understudied career self-management (CSM) with personenvironment fit research, this study aims to assess the unique effects of person-organization, person-coworkers and needs-supplies fits on employees' deployment of career advancement strategies. A questionnaire was completed by 548 highly educated young Kuwaitis and self-initiated expatriates (Arab and South Asian) working in medium and large Kuwaiti organizations. The simultaneous effects of the three types of fits is assessed and the findings demonstrate that an increase in person-coworkers fit and decrease in person-organization and needs-supplies fits consistently encourage the deployment of career advancement strategies concerning accessing influential networks, self-promotion, competence building and psychological boundaryless. A relatively more robust effect of person-coworker fit has been detected. It is attributed to the Arab collectivistic culture and to the construct being a career competency and a contextual factor as per the "intelligent career" theory. Interventions should be mindful of the differential effects of different types of fit on CSM. Developing organizational 'standards of fit' and CSM skills are essential for individual career development and organizational success. The study provides unique information about the understudied constructs of CSM and person-environment fit in a traditional and high inequality Arab Middle Eastern country, and infers the causes of the inconsistent effects of contextual factors reported by previous studies.
\end{abstract}

Keywords: person-organization values fit, person-coworkers support fit, needs-supplies career fit, career self-management (CSM), Arabs, employees

\section{Introduction}

Economic pressures are leading to shifts from corporate careers, where the corporation is the primary career driver, to protean careers where employees largely manage their own careers (Baruch, 2014). Recent studies have ascertained the spread of what Arthur, Inkson and Pringle (1999) have termed a 'new career'. The new career which includes protean and boundaryless careers - contrasts with the traditional, secure, hierarchy-based career. Due to the increase in new careers and the political nature of organizations, career self-management (CSM) is, more than ever, deemed to be a high-leverage concept for enhancing individuals' career success (Briscoe \& Hall, 2006; De Vos \& Soens, 2008; King, 2001). CSM involves sculpting one's career by changing self and/or the situation, instead of only reacting to the situation. Parker and Collins (2010) argued that CSM is a form of proactive person-environment fit (P-E fit or fit) behavior, because it initiates change to achieve greater compatibility between individuals' own needs and attributes and their environments. This study intends to examine the unique effects of three types of fit on motivating CSM of young professionals in Kuwait. Specifically, it intends to examine the unique contributions of person-organization values congruence (PO fit), needs-supplies fit (N-S fit) and person-coworkers support fit (hereafter referred to as PG fit) on employees' deployment of career advancement strategies. Enhancing fit augments one's strategic competitive position and requires proficiency in tactical, social and identity-related tasks such as building networks and competencies, self-promotion, seeking better job and feedback (King, 2001; Gubler et al., 2014). Thus, protean and boundaryless career attitudes, political savviness, and knowledge about P-E fit and unwritten organizational rules (Carter \& Silva, 2011; Direnzo \& Greenhaus, 2011) relate to the tasks just described. Indeed, mainstream research in the last century focused largely on traditional careers, so it is important to recognize the new dynamics and turn the focus of research on the 'new career,' particularly in relation to its environment. 
CSM is relevant to P-E fit because it focuses on long-term compatibility between an individual's career expectations and the organization's requirements. The P-E fit has been theoretically and empirically linked to individual and organizational outcomes. However, little research has been done on the relation between fit and CSM (Parker et al., 2010; Kostal \& Wiernik, 2017). The lack of research investigating this theoretical proposition is especially surprising given the large amount of P-E fit research going back more than a century. Another shortcoming in the fit literature revealed by Kristof-Brown, Zimmerman and Johnson's (2005) meta-analysis study and by other studies, is the rarity of research focusing on P-E multi-dimensionality. Kristof-Brown et al. (2005) stressed the importance of assessing the unique contribution of each kind of fit because people assess different aspects of their environments separately. So far, only a few types of fit have been studied, the PO fit being the most studied. Empirical studies which simultaneously examined different types of fits have found that the fits differentially relate to employee attitudes and behaviors (Greguras \& Diefendorff, 2009). This led to calls for more research on the understudied fits and for research exploring new kinds of fits (e.g., Kristof-Brown et al., 2005). There have also been calls for research into the relations between different kinds of fits and different types of proactive career behavior (Parker \& Collins, 2010) and particularly in high inequality societies (Kostal \& Wiernik, 2017).

Understanding the role of different types of P-E fits within the career development domain has, therefore, both theoretical and practical significance because research into the conditions that foster or undermine people's career development helps to advance formal knowledge of the causes of organizational outcomes and human behavior and wellbeing (Ryan \& Deci, 2000). Consistent with the calls of Parker and Collins (2010), this paper aims to contribute to the recent efforts to integrate the literature on CSM and fit by examining the effects of PO, PG and N-S fits on employees' deployment of career advancement strategies. This is done through analyzing these relationships in a sample of highly educated young Kuwaitis and self-initiated expatriates (SIEs, specifically Arabs and South-Asians) working in Kuwait. The choice of the fits was based on their relevance to CSM (Parker \& Collins, 2010), and was also guided by the suggestions of Werbel and Gilliland (1999) who stated that assessing PO fit should be based on values and/or needs, and that assessing PG fit should be based on interpersonal attributes and broad-based proficiencies. Mayo et al. (2012) indicated that coworker support had a more consistent effect in managing specific stressors - such as nonlinear career challenges - than supervisor support. Parker and Collins (2010) stressed the relevance of person-job fit (i.e., N-S fit and demand-abilities fit) as antecedent to CSM. Ashford \& Black (1996) and Cable and DeRue (2002) found that N-S fit is more effectual predictor of individual behavior than demand-abilities fit which is more relevant to organizations.

Consistent with the suggestions just described, this study adopts the PO fit construct (Cable \& DeRue, 2002), which is commonly used in supplementary fit research tradition. PO fit refers to the congruence between the employee's values and organizational values and culture. The PG fit used here refers to the correspondence between the employee's needs and perceived coworkers' support, and N-S fit refers to the correspondence between employees' needs and the amount of rewards their jobs offer (Cable \& DeRue 2002; Seong \& Kristof-Brown, 2012). N-S fit and PG fit are part of the complementary fit research tradition. The three fits of this study are consistent with Kristof's (1996: 4-5) definition of fit which integrates the complementary and supplementary fit traditions as follows: “... the compatibility between people and organizations that occurs when: (a) at least one entity provides what the other needs, or (b) they share similar fundamental characteristics, or both". These traditions represent distinct research streams within the P-E fit paradigm (Cable \& Edwards, 2004). In response to calls to integrate the two traditions, this study is following a method used by Cable and Edwards, (2004), which utilized and analyzed constructs from both traditions simultaneously to predict their unique effects on employee behavior.

Regarding CSM literature, recent reviews (e.g. Gubler et al., 2014; Kostal \& Wiernik, 2017), have indicated that most research was theoretical, attitudinal and focused mainly on the outcomes of behavior. The empirical studies were Western-centric and focused primarily on tertiary students. Thus, there is need to extend research on CSM and its antecedents to non-Western regions (Gubler et al., 2014; Kostal \& Wiernik, 2017; Segers et al., 2008). To the best of our knowledge there is only one study on antecedents of CSM in the Arab Middle Eastern region and it focused on demographic differences in protean behavior (Abdalla, Al-Homoud \& Muhammad, 2019). This study, therefore, contributes to the literature by examining the effects of contextual antecedents on CSM in Kuwait. Although culture is not the primary focus of this study, it is useful to explore the applicability of the protean career and P-E fit concepts to Arabs, whose societal values emphasize high in-group collectivism, power-distance (obedience to authority), uncertainty avoidance, resistance to change, and masculinity (Abdalla, 2006; Hofstede, 2001). Agency, self-directedness, risk-taking and change orientation, which are inherent in the protean career construct, have less of an expression in Arab culture. The protean construct, therefore, might not be easily transferable to the Arab workplace. On the other hand, Arab societal values of conformity, comradeship and 
fitting-in with the larger group may make their responses to P-E mismatch different, perhaps milder than those of Westerners. Consequently, the relationships between P-E fit and CSM in the Arab region might not mirror the results of western-based studies.

We address two preliminary questions related to CSM and P-E fit. First, do the different kinds of fit namely, PO, PG and N-S fits have different effects on CSM? That is, what are the unique contributions of each fit when they are simultaneously assessed? In this regard, Cable and Edwards (2004) and Kristof-Brown et al. (2005) suggested that research comparing the effects of simultaneous assessments of multiple kinds of fit is needed. Second, given the Arab culture where fitting in and getting along is more important than getting ahead (Abdalla, 2006), do the findings echo the relationships found in Western cultures? With the scarcity of research on CSM in general and particularly in its relation to specific P-E fits, the answers to these questions will contribute to the literature on CSM and fit. Also, they will provide a better understanding of how these important constructs apply cross-culturally. The remainder of this paper is structured in the following manner. First, it describes the current call for research on different kinds of P-E fit and CSM, and the effect of fit on CSM (represented here by deployment of career advancement strategies), and their theoretical base as well as empirical findings. Next, it integrates CSM and fit research into three hypotheses. The method and analysis are then presented. The results are discussed within the literature and Arab socio-political environment. The paper also advocates studying specific types of P-E fit as related to CSM to advance our understanding of the understudied protean career, and to further the development and sustainability of employees' careers and organizational outcomes. In this paper career, proactive behavior, protean behavior, proactivity and CSM are used interchangeably.

\section{Literature Review}

\subsection{Career Proactive Behavior}

One of the most innovative contributions to capturing the changing nature of careers has been the research in the protean career (Briscoe \& Hall, 2006), a concept that is complementary to the boundaryless career (Arthur \& Rousseau, 1996). Given the increasing employment pressures, the protean career is gaining increased attention from researchers and practitioners. Baruch (2014) stated that there was accelerated interest in the concept of protean career and its applications, both in Western and in global contexts. Protean career orientation is a contract with oneself, rather than between oneself and an organization, leaving much of the career development to the individual's initiation and proactivity, and in which self-management is paramount (De Vos \& Soens, 2008). CSM entails charting the career landscape, knowing the decision-makers who influence one's career (the Gatekeeper) and deploying strategies to enhance one's strategic positioning and influencing effectiveness (Seibert, Kraimer \& Crant, 2001; King, 2001). Hence, it aims to enhance the P-E fit by changing self and/or the environment (Parker and Collins, 2010) and by utilizing strategies to increase career opportunities and eliminate threats (Briscoe \& Hall, 2006).

A wide variety of career advancement tactical behaviors were studied, however, most studies focused on students' job search and employees' training (Gubler et al., 2014). Among the few studies that simultaneously assessed a wide spectrum of career advancement strategies is Carter and Silva's (2011) study. Their study covered a variety of tactics such as seeking access to high profile assignments, influential networks, visibility, support, feedback, training and knowledge about labor markets and political landscape. Theoretically, it is well established that engagement in such strategies is a function of the interaction between environmental factors and individual ones (Ng, Sorensen, Eby \& Feldman, 2007). Even people with protean and boundaryless career orientations have to comply with certain organizational and contextual boundaries (Baruch, 2014). It is, therefore, important to study the impact of contextual factors such as PO, PG and N-S fit on CSM. Below we present a brief clarification of the $\mathrm{P}-\mathrm{E}$ fit constructs and review of relevant research.

\subsection{P-E Fit}

\subsubsection{Clarifying the Conceptual Differences between the Constructs}

Researchers have drawn from the supplementary and complementary traditions of the P-E paradigm to predict outcomes that span all stages of work life, ranging from career and organization choice, to job satisfaction and stress to decisions to change the situation (e.g., quit) or change self (e.g., develop new skills). Complementary fit approach, of which N-S and PG fits are part, occurs when the weaknesses or needs of the individual are offset by the environment or vice-versa (Cable \& Edwards, 2004). That is, N-S fit and PG fit used in this study refer to occasions when an entity (i.e., organization or coworkers) offers the amount of reward/support that an employee wants. In contrast, PO fit, like other supplementary fits, exists when a person and an organization possess similar or matching attributes (e.g., skills or values) that both consider important (Cable \& Edwards, 2004). For example, when both the employee and organization consider job security to be important. Thus, the difference between 
$\mathrm{N}-\mathrm{S}$ and PG fit and PO values fit is that the first two constructs focus on the amount of the attribute received from the job or coworkers while the latter focuses on the importance of the attribute/value. In this regard Cable and DeRue (2002: 876) stated, "Theoretically, the fit between the employee's needs and the rewards that emanate from the job is quite distinct from .... values congruence". They noted that a job could deliver needed rewards even if the job incumbent did not fit the organization's values. This is because N-S fit is based primarily on job outcomes. Their study and many others tested and refuted the assumption that employees' value congruence with organizations is one specific form of N-S fit and therefore one of many job rewards. In this respect Cable and Edwards (2004) stated that both N-S fit and value congruence independently affect employee attitudes and outcomes, such that each predicts attitudes and outcomes when the other is controlled. They asserted that N-S fit and value congruence represent distinct theoretical processes with unique effects on employee attitudes and behavior. It was found that people form separate cognitions about their fit with their organization's cultural values (PO fit), and their fit with their job in return for their service (N-S fit) as well as about the fit with their coworkers in terms of the support received (PG fit). Hence, a 'simultaneous effects' perspective has been recommended by several researchers to determine the unique contributions of these kinds of fit (Cable and Edwards, 2004; Greguras \& Diefendorff, 2009). These suggestions are consistent with the P-E framework offered by Kristof (1996) which depicts both complementary and supplementary fits as separate processes with different underlying logic.

\subsubsection{PO Fit}

As mentioned above, value congruence is a very prominent concept within the supplementary tradition of the P-E paradigm and organizational behavior research. In this stream of research, values are beliefs that transcend specific situations, pertain to desirable end state or behavior, guide choice of behavior or events and vary in terms of relative importance (Schwartz, 1992). Theoretically and empirically it is suggested that employees with higher PO fit have more positive work attitudes and feel involved with the broader mission of the organization. The logic is that individuals like to work in environments that reinforce their self-concept. The accruing gratification was empirically linked to low turnover, increased employee embeddedness in their organizations and to decreased engagement in CSM (Tak, 2011; Parker et al., 2010). It would be interesting to know whether these results are supported in high power distance and low agency societies. In such societies, subjugation of personal interest to leaders' interest is encouraged. Thus, we propose:

Hypothesis 1: PO fit discourages engagement in CSM and PO incongruence enhances it.

\subsubsection{N-S Fit}

CSM is theoretically and empirically linked to Person-Job fit concept (Edwards, 1991; Parker et al., 2010). Proactive behavior is more energized by perceptions of unfairness, imbalance or mismatch in needs-supplies and demand-abilities, particularly when individuals feel safe and valued, and when the cost of failure is low. Wang et al. (2014) argued that N-S fit at the workplace signals that the current employment provides worthwhile return on investment and meaningful experiences, which encourage employees to embed in the organization and lower their proactivity. In contrast, N-S mismatch suggests negative contexts and psychological contract breach. Hence it motivates people to initiate protean and/or boundaryless tactics in order to pursue meaningful careers (Hirschi et al., 2013; Parker \& Collins, 2010). Thus, an examination of the presumed negative effect of the match between individual career growth needs and job rewards (N-S fit) on the variance of CSM is warranted. Therefore, it is proposed that:

Hypothesis 2: Perceived N-S fit decreases engagement in CSM and mismatch in needs and supplies enhances it.

\subsubsection{PG Fit}

Research has emphasized the importance of interpersonal relationships within the work setting, particularly in relation to coping with today's employment pressures (Mayo et al, 2012). Supervisors, colleagues and subordinates are important sources of the emotional and technical support that is needed to effectively engage in CSM. Thus, the fit between the employee's needs and the perceived support of coworkers is considered crucial for career success (Werbel \& Gilliland, 1999). Many theories and empirical studies have linked social capital with effective CSM and career success. For example, Arthur, Claman, and DeFillippi (1995) argued that "knowing whom', "knowing how" and "knowing why" are essential competencies for "intelligent careers". For Arabs, the PG fit construct, "knowing whom" competency and comradeship are especially important, because of Arabs' high in-group collectivistic culture (Abdalla, 2006; Hofstede, 2001).

It is important to note that previous research has found that support from supervisors, a frequently offered 
prescription in the practitioners' guidelines, is not as consistently positive in lowering stress as that of coworkers (Mayo et al., 2012). It was found that when supervisors are perceived as sources of stressors (e.g., career barriers), their support makes matters worse by magnifying the negative impact of the stressors - perhaps due to the employees mistrusting the supervisors' sincerity. However, when the source of employees' stressors is unlinked to the supervisor, the supervisor will be in a better position to alleviate the negative consequences of stress. In contrast, most career systems are beyond the control of coworkers. Employees, therefore, are less likely to identify coworkers as their career stressors and, consequently, coworkers' support might be more effectual than supervisors' support in enhancing CSM (Mayo et al., 2012). For these reasons, and others, the coworkers' support construct is used as one of the antecedents of CSM in this study. Specifically, the reasons for including coworkers construct are: First, coworkers are important sources of support for employees. Second, although coworkers can certainly influence work dynamics, they do not typically have the authority to shape employee work assignments and careers in the manner that supervisors do. Consequently, employees are less likely to attribute career barriers to coworkers, and a reverse effect for coworkers' support is not expected. Instead, having supportive coworkers encourages employees to vent their frustrations, provide fresh ideas that help them cope with career challenges and coach them to develop new ways to manage their careers. Third, supervisors shape the career context. Also, in this study supervisors' values and support are incorporated in the PO fit and N-S fit constructs respectively. Due to these overlaps, it was decided to include a coworkers' support construct rather than a supervisor's support construct. Further, we argue that high PG fit is expected to be positively related to CSM because the construct is competence-based (Arthur et al., 1995; Cable \& DeRue 2002) and provides the support and empowerment needed to engage in CSM. Thus, we propose:

Hypothesis 3: PG fit encourages CSM and lack of PG fit dampens it.

\section{Method}

\subsection{Procedure and Participants}

The participants were 548 highly educated employees working in various medium to large public and private Kuwaiti organizations. The questionnaires were administered by the research team through their contacts in those organizations. The respondents' voluntary participation was requested by the team, no formal involvement of the management of the organizations was solicited and no payments were made to any of the participants. The response rate was $71 \%$. Fifty four percent of the sample was from the private sector, $52 \%$ were men, $58 \%$ were Kuwaitis, $42 \%$ were Arab and South Asian SIEs, $79 \%$ were married, $72 \%$ had bachelor's degrees, and $28 \%$ had graduate degrees. Ages ranged from 24 to 49 years (35\% were below 30 years; 38\% were between 30-39 years and $27 \%$ were between $40-49$ years).

\subsection{Measures}

\subsubsection{Career Advancement Strategies}

Employees' career advancement strategies were measured utilizing a 19-item scale developed by Carter and Silva (2011) which assesses employees' strategies for discerning the career competitive landscape, seeking better capabilities, feedback, visibility, opportunities inside and outside the organization, networking, and for getting/providing support. The total scale has Cronbach Alpha reliability score $(\alpha=0.92)$. The scale was originally used by Carter and Silva (2011) on a sample of 3,345 high potential employees of Fortune Global 500. The respondents were asked to think of their overall career since completing their last degree and determine the extent to which they actively used each of the 19 tactics. A 5-point scale ("not at all" to "a great extent") was used.

\subsubsection{PO, N-S and PG Fits}

PO and N-S fits were measured by commonly used scales of Cable and DeRue (2002). Each scale consists of 3 items. Since PG fit in this study is conceptualized as the match between coworkers' support and the participant's needs, a modified version of the N-S fit scale was used by replacing the word 'job' by 'coworkers' and the statements were adjusted accordingly, as recommended by Cable and DeRue (2002). Other researchers (e.g., Greguras \& Diefendorff, 2009) made similar changes to Cable and DeRue's (2002) scales to measure different fits. That is, the three items of the PG fit scale used in this study asked participants to evaluate the extent to which their coworkers provided them with the needed support. Sample items for each scale and Cronbach Alpha reliability scores are as follows: PO fit: "The things that I value in life are very similar to the things that my organization values," $(\alpha=0.83) ; \quad \mathrm{N}-\mathrm{S}$ fit: "There is a good fit between what my job offers me and what I am looking for in a job", $(\alpha=0.89)$; PG fit: "There is a good fit between the support I need to do my job and the support provided by my coworkers", $(\alpha=0.87)$. All fit items were responded to using 5-point scales, ("not at all" 
to "completely"). All scales were translated into Arabic using a translation-back-translation procedure (Brislin, 1970).

\section{Analysis and Findings}

\subsection{Factor Analysis}

An exploratory factor analysis was performed on the 19 items of the career advancement strategies scale (Carter \& Silva, 2011). Factor loading of $\geq 0.55$ was accepted which is slightly higher than the score recommended by Hair et al. (2006), and no cross loading larger than 0.50 was accepted. One item ("I make sure my supervisor knows I am willing to work long hours and/ or weekends") did not satisfy the criteria and was excluded from the analysis. A four-factor solution was produced. The correlation between the factors was not high enough to suggest a major overlap between them (Table 1). Like the findings of Carter and Silva (2011) and Briscoe and Hall (2006), the factors suggest that individuals use tactics in groups. The groups were labeled to reflect their contents and to match the labels used in previous research, i.e., Access-to-power, Self-promotion, Psychological Boundaryless, and Competence building. The number of items per factor, Cronbach Alpha reliability scores and sample items are as follows: Access-to-power (5 items; $\alpha=0.80$; "I get myself introduced to people in my organization who can influence my career"); Self-promotion (4 items; $\alpha=0.80$; "I make sure I get credit for the work I do"); Psychological Boundaryless (5 items; $\alpha=0.85$; "I make sure I remain informed about my market value and opportunities"); Competence building (4 items; $\alpha=0.77$; "I am proactive in getting new job competencies through training and development programs"). The analysis produced distinct strategy groups with high reliability scores, therefore, the total score of the 19 items was not used (Hair et al., 2006). The results support the measure's internal consistency and construct validity and extended its external validity to the Middle Eastern cultures.

Table 1. Means, standard deviations, and correlation coefficients

\begin{tabular}{|c|c|c|c|c|c|c|c|c|c|c|c|}
\hline & $\begin{array}{l}\text { Mean } \\
\text { (SD) }\end{array}$ & Gender & Nationality & Age & Experience & A to $P$ & PB & SP & CB & PG fit & $\begin{array}{l}\text { N-S } \\
\text { fit }\end{array}$ \\
\hline $\begin{array}{l}\text { Nationality } \\
\text { Age }\end{array}$ & $\begin{array}{l}- \\
-\end{array}$ & $\begin{array}{l}-.094 * \\
-.169^{* *}\end{array}$ & $.194^{* *}$ & & & & & & & & \\
\hline Experience & - & -.146 & $.181^{* *}$ & & & & & & & & \\
\hline A to $\mathrm{P}$ & $\begin{array}{l}3.55 \\
(.86)\end{array}$ & $-.158^{* * *}$ & -.027 & -.017 & -.016 & & & & & & \\
\hline PB & $\begin{array}{c}3.3 \\
(.89)\end{array}$ & -0.058 & -.028 & $-.140^{* * *}$ & $-.156^{* *}$ & $.573^{* *}$ & & & & & \\
\hline SP & $\begin{array}{l}3.6 \\
(.92)\end{array}$ & -0.038 & $-.162^{* *}$ & $-.127^{* *}$ & $-.130^{* *}$ & $.503^{* *}$ & $.573^{* * *}$ & & & & \\
\hline $\mathrm{CB}$ & $\begin{array}{l}3.6 \\
(.81)\end{array}$ & $-.086^{*}$ & -0.026 & $-.094^{*}$ & $-.100^{*}$ & $.613^{* *}$ & $.645^{* *}$ & $.440^{* *}$ & & & \\
\hline PG fit & $\begin{array}{l}3.6 \\
(.72)\end{array}$ & -0.055 & 0.060 & $-.091^{*}$ & $-.110^{*}$ & $.252^{* *}$ & $.180^{* *}$ & $.170^{* *}$ & $.236^{* *}$ & & \\
\hline N-S fit & $\begin{array}{c}3.4 \\
(.77)\end{array}$ & $-.097^{*}$ & 0.067 & .041 & .001 & -0.062 & $-.169^{* *}$ & $-.090^{*}$ & $-.091^{*}$ & $.310^{* * *}$ & \\
\hline PO-fit & $\begin{array}{c}3.3 \\
(.87) \\
\end{array}$ & 0.007 & 0.076 & .049 & .032 & $-.200^{* *}$ & $-.308^{* *}$ & $-.163^{* *}$ & $-.197^{* *}$ & $-.112^{* *}$ & $.254^{* *}$ \\
\hline
\end{tabular}

$* * \mathrm{P} \leq .01 ; * \mathrm{P} \leq .05$; Nationality: Kuwaiti $=1, \mathrm{SIE}=2$; Gender: male $=1$, female $=2$. A to P, PB, SP, CB refer to Access to power, Psychological boundaryless, Self-promotion and Competence building, respectively

\subsection{Cluster Analysis}

Following the method used by Carter and Silva (2011) and Briscoe and Hall (2006) we explored whether meaningful clusters of people with different career advancement strategic orientations could be identified. Using the four factors (i.e., groups of strategies) we applied a two-step Cluster Analysis (Hair et al, 2006) which produced a solution of two clusters. All four factors differentiated one cluster from the other. Guided by the content of each cluster and the labels used by previous research (e.g., Seger et al., 2008), the cluster of people with a strong protean career orientation is labeled "Hunter" and the one with weak protean orientation is labeled "Dependant" (Figure 1). The Cluster Analysis on the four strategy groups produced two distinct career strategic orientations, indicating that the participants follow one of two distinct career self-management orientations to advance their careers. The Hunters, who represent $53 \%$ of the sample, have stronger protean orientations and use 
all four strategy groups more than the Dependants. In contrast, the Dependants rely largely on their employers to manage their careers (Figure 1). Thus, the results extend the construct validity of the measure to the Arab region. The study controlled for the effects of gender, age, work experience and nationality (Kuwaiti, non-Kuwaiti) which are generally related to CSM. Since the variance in the respondents' education was small (university degree or higher) and had an insignificant effect on the results, it was removed from the analyses.

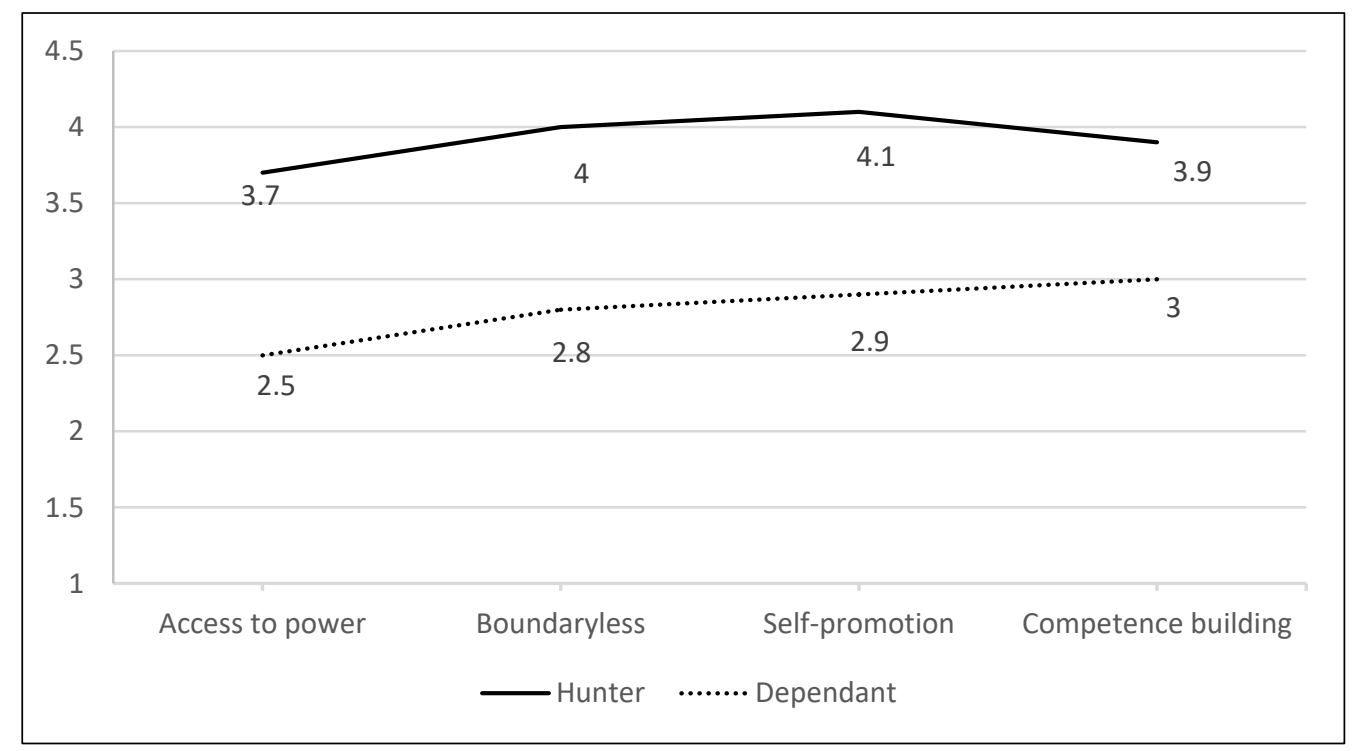

Figure 1. Two-step cluster analysis: Hunter and Dependant strategic orientations

\subsection{Addressing the Hypotheses}

Descriptive statistics and correlation coefficients are presented in Table 1. Hierarchical linear and logistic regression analyses were used to address the three research hypotheses. Hierarchical linear regression assessed the unique contributions of PO, PG and N-S fits (independent variables) to the variance in the deployment of the four strategy groups (dependent variables; Tables 2). Table 3 presents the results of the hierarchical logistic regression analysis (Wald test) which assessed the impact of the PO, PG and N-S fits on the two strategic orientations (i.e., dependent variables, namely, Hunter and Dependant).

The results of the hierarchical linear regression analysis pertaining to the effects of PO, PG and N-S fits on the four types of strategy groups confirmed the three hypotheses (Table 2). The results show unique and consistent effects of the three types of fit on each of the four groups of career advancement strategies. As predicted, the directions of the effects are different; PG fit has a positive effect on the strategy groups and PO and N-S fits have negative effects. Also, PG fit seems to be more effectual than PG and N-S fit in predicting the four strategy groups. Specifically, the results suggest that employees increase the deployment of the four types of career advancement strategies when they have supportive coworkers (PG fit), when their needs are not fulfilled by their jobs and/or their values conflict with their organizations' values and culture. As for the career strategic orientations, the logistic regression results (Table 3) show that the likelihood of individuals to have Hunter rather than Dependant career orientations is doubled if they have PG fit and is reduced by $25-30 \%$ if they have either PO fit or N-S fits. The control variables (covariates) show that the likelihood of being a Hunter is lower by $20 \%$ to $38 \%$ if the participant is a female, older in age, non-native or with longer years of experience. That is, Hunter orientation is stronger among Kuwaitis, men, younger employees and those with fewer years of experience. 
Table 2. Hierarchical linear regression: PO, PG and N-S fits as predictors of career advancement strategies

\begin{tabular}{|c|c|c|c|c|c|c|c|c|c|c|c|c|c|c|c|c|c|}
\hline \multirow[t]{2}{*}{$\#$} & & \multicolumn{4}{|c|}{ Access to power } & \multicolumn{5}{|c|}{ Psychological boundaryless } & \multicolumn{3}{|c|}{ Self-promotion } & \multicolumn{4}{|c|}{ Competence building } \\
\hline & & $\begin{array}{c}\text { Stand. } \\
\beta\end{array}$ & $\mathrm{t}$ & $\mathrm{P}$ & $\begin{array}{c}\text { Adj. } \\
\text { R2 }\end{array}$ & $\begin{array}{c}\text { Stand. } \\
\beta\end{array}$ & $\mathrm{t}$ & $\mathrm{P}$ & $\begin{array}{c}\text { Adj. } \\
\text { R2 }\end{array}$ & $\begin{array}{c}\text { Stand. } \\
\text { B } \\
\end{array}$ & $\mathrm{t}$ & $\mathrm{P}$ & $\begin{array}{l}\text { Adj. } \\
\text { R2 }\end{array}$ & $\begin{array}{c}\text { Stand. } \\
\beta\end{array}$ & $\mathrm{t}$ & $\mathrm{P}$ & $\begin{array}{c}\text { Adj. } \\
\text { R2 }\end{array}$ \\
\hline \multirow[t]{4}{*}{1} & Nationality & -.07 & -1.73 & .09 & .029 & -.01 & -.32 & .75 & .023 & .16 & -3.8 & .00 & .039 & .01 & .33 & .74 & .017 \\
\hline & Gender & -.18 & -4.47 & .00 & & -.10 & -2.31 & .02 & & -.09 & -2.22 & .05 & & -.12 & -3.03 & .00 & \\
\hline & Age & .04 & -.18 & .23 & & -.16 & -3.82 & .00 & & -.12 & -2.86 & .00 & & -.11 & -2.63 & .01 & \\
\hline & Experience & .05 & -.19 & .20 & & -15 & -.3 .65 & .00 & & -10 & -2.81 & .00 & & -.10 & -2.43 & .01 & \\
\hline \multirow[t]{3}{*}{2} & PO fit & -.13 & -3.19 & .00 & .124 & -.24 & -5.98 & .00 & .150 & -.09 & -2.29 & .02 & .092 & -.14 & -3.60 & .00 & .130 \\
\hline & PG fit & .27 & 6.48 & .00 & & .19 & 4.72 & .00 & & .20 & 4.87 & .00 & & .29 & 7.19 & .00 & \\
\hline & $\mathrm{N}-\mathrm{S}$ fit & -.14 & -3.28 & .00 & & -.17 & -4.15 & .00 & & -.12 & -2.86 & .00 & & -.13 & -3.02 & .00 & \\
\hline
\end{tabular}

Note. $\#=$ Step, Nationality: Kuwaiti $=1, \mathrm{SIE}=2 ;$ Gender: male $=1$, female $=2$.

Table 3. Hierarchical logistic regression: PO, PG and N-S Fits as predictors of Hunter and Dependant career orientations

\begin{tabular}{lllllll}
\hline Step & & B & (SE) & Wald & P & $\operatorname{Exp}(\mathrm{B})$ \\
\hline 1 & Nationality & -.49 & .18 & 7.92 & .005 & .611 \\
& Gender & -.48 & .18 & 7.15 & .008 & .617 \\
& Age & -.22 & .09 & 5.36 & .024 & .800 \\
& Experience & -.20 & .08 & 4.78 & .033 & .800 \\
2 & PO fit & -.29 & .11 & 7.53 & .006 & .747 \\
& PG fit & .68 & .14 & 24.51 & .000 & 2.01 \\
& N-S fit & -.46 & .129 & 12.86 & .000 & .630 \\
\hline
\end{tabular}

Note. Strategic orientation: Dependant $=1$, Hunter $=2$; Nationality: Kuwaiti $=1$, SIE $=2 ;$ Gender: male $=1$, female $=2$.

\section{Discussion}

Previous research has demonstrated the importance of contextual beliefs in predicting proactive career behavior (Briscoe et al., 2012; Lent \& Brown, 2013; Ng et al., 2007) and calls were made for further examination of the influence of different types of P-E fit on CSM and extending CSM research to non-Western cultures (Gubler et al., 2014; Parker \& Collins, 2010; Kostal \& Wiernik. 2017). Specific calls were made for studying the role of N-S and PG fit on employees' attitudes and behavior (Cable \& DeRue, 2002; Greguras \& Diefendorff, 2009). In response to these calls we utilized a sample of highly educated young native and expatriate employees working in Kuwait to assess the unique impact of perceived PO, PG and N-S fit on CSM. The aim was to determine the unique effects of different types of fit on different types of career strategy, and to reveal the nature of the relationships and the validity of these constructs in an Eastern culture. To our knowledge this study is one of only a few studies which have examined the fit in relation to CSM, and the first to examine these relations in the Arabian Gulf region. For this purpose, the study is informed by P-E fit, career and organizational justice literature to hypothesize that low PO, and N-S fits and high PG fit encourage career proactive behaviors. Generally, the findings support our hypotheses and previous research (e.g., Greguras \& Diefendorff, 2009; Kristof-Brown et al., 2005) which found that different kinds of fit lead to different individual attitudes and behaviors.

Our results indicate that different conceptualizations of fit uniquely predict and differentially relate to the deployment of career advancement strategies, such that low PO and N-S fits and high PG fit lead to a Hunter career orientation and encourage employees' utilization of strategies like seeking access to influential individuals, increasing job variety and significance, monitoring internal and external employment opportunities, self-promoting, and skill development. That is, individuals who are unsatisfied with the organization's values and job rewards and have supportive employees seek to change self and/or the environment to augment the fit. This, in turn, improves their strategic positioning and career progress. In support, previous findings indicated that protean initiatives are motivated by low P-E fit and the desire to fit in (e.g., Carter \& Silva, 2011; Parker \& Collins, 2010) and by social capital (Arthur et al., 1995). Conversely, employees who are satisfied with their organizations' values and culture as well as their job rewards (i.e., they have high PO and N-S fit), but are experiencing poor coworker support (i.e., PG mismatch) would be least motivated to engage in CSM. This group is likely to have Dependant career orientation which may lead to loss of future career success (Baruch, 2014; Gubler et al., 2014). A third scenario concerns individuals who are largely fitting in the organization in terms of being satisfied with organizational cultures, job rewards and coworkers support. This group's motivation to 
engage in CSM can be sourced from coworkers' support.

The covariates reveal that Kuwaitis, men, and young and less experienced employees are more likely to have Hunter career orientation than their counterparts have. These results are consistent with the findings of Abdalla et al. (2019). These authors attributed the demographic differences in protean career behaviors to the Kuwaiti segmented labor market by gender and nationality. Also, the gender and age results are consistent with previous research (Segers et al. 2008), and with the highly masculine Arab culture which values age and seniority. The lower proactivity of SIEs is interesting as SIEs are considered an embodiment of proactive behavior (Cao et al., 2012). This may be attributed to their restrictive work environment in Kuwait (Hertog, 2012; Abdalla et al., 2019) and perhaps to poor management. Previous research has shown that managers were often unprepared to effectively manage expatriates (McEvoy \& Buller, 2013). Below, we will discuss each of the fits separately.

\subsection{PO Fit}

The findings suggest that when there is congruence between the employees' and organizations' value systems, individuals are likely to be less proactive, have Dependant career orientation and lower the deployment of all career advancement strategies, namely Access to power, Psychological boundaryless, Self-promotion and Competence building. The unique and consistent negative effects of PO fit on the four strategy types understudy, after controlling for N-S and PG fits, support the validity of these relations. The results substantiate career theories and empirical findings which suggest that positive environment discourages proactive behavior (Hirschi et al., 2013; Kostal \& Wiernik, 2017). They are also consistent with P-E fit studies (e.g., Cable \& Edwards, 2004; Cable \& DeRue, 2002; Greguras \& Diefendorff, 2009) which found unique positive effects of PO fit on organizational identification, citizenship and turnover decision when controlling for N-S fit, PG fit and other types of fit. The positive effect of PO fit on numerous types of behaviors and its negative effect on proactive behavior are expected because proactivity is often triggered by stressors. In this regard, Parker et al. (2010) and Cable and Edwards, (2004) argued that contentment with the fit between self-concept and organizational culture may encourage embeddedness and willingness to align one's career with that of the organization, which, in turn, lowers the need for proactive career behavior. In other words, when employees' and organizations' values converge, collaborative spirit develops and employees become more contented, optimistic of a harmonious relation with their organization, and committed to the organization mission, and thus their proactive tendencies and desire to change the situation dampens. Conversely, when the values of the employees and organizations diverge, collaboration may diminish, and careers become contested terrains in which the organizations pursue strategic advantages based on their values and employees pursue personal advantages based on different sets of values. Consequently, employees engage in more proactive behaviors to protect their interests (Inkson \& King, 2011). These arguments are supported by empirical findings which revealed that negative environments are stronger instigators of proactivity than positive ones (Lent \& Brown 2013) because there is more need to take personal initiatives and corrective measures in challenging times (Briscoe et al., 2012). These explanations are consistent with Schneider's (1987) attraction-selection-attrition model, which posits that employees are attracted to join and stay in organizations that share similar characteristics or values to their own. Thus, our results substantiate current efforts to bridge PO fit and CSM theories.

\section{$5.2 \mathrm{~N}$-S Fit}

$\mathrm{N}-\mathrm{S}$ fit is a component of the person-job fit. The findings suggest that, like PO fit, low N-S fit encourages engagement in CSM. That is, when employees perceive a poor correspondence between their career growth needs and the amount of job rewards, they tend to rectify the situation by intensifying the deployment of all four strategy types. For example, they may seek more access to their 'career gatekeepers', engage in self-promotion and skill development and search for alternative employment opportunities. These findings are consistent with organizational and vocational behavior research (Crawshaw et al, 2012; Hirschi et al 2013; Wang et al., 2014) which attests that incongruence and injustice are strong motivators of both boundaryless and protean career behaviors. The underlying premise linking N-S fit to CSM is that needs are the starting point of motivation, because employees expect that their jobs, careers and professions satisfy certain needs (Locke, 2000). When employees perceive N-S fit at the workplace, they are likely to experience meaningful careers which, in turn, may increase contentment and organization commitment and lower proactive behavior (Parker et al., 2010). However, if N-S fit is low, this may signal violation of their psychological contract due to failure of the current employment to provide a worthwhile returns on their investment (Rousseau, 1998). Hence, they may intensify the deployment of protean and boundaryless tactics to remedy the situation (King, 2001). These findings substantiate Inkson and King's (2011) arguments presented above, regarding the conflict accruing from employees' and their organizations' divergent interests. Yet, CSM is seldom easy to deploy because proactive behavior is risky by nature, therefore, it is pursued when the work environment is 
conducive for the expression of one's cognitive, emotional and physical selves without threat to their self-concept, dignity, status or career (Kahn, 1990). Thus, PG fit might provide the encouragement needed to engage in CSM. Interestingly, despite the high context culture of Kuwait, the findings of $\mathrm{PO}$ and $\mathrm{N}-\mathrm{S}$ fit substantiate previous Western-based research and show that incongruencies in the employees' and organizations' values and employees' unfulfilled needs tend to encourage protean career behaviors. Thus, the study extends the N-S fit and CSM constructs' validity to the Middle Eastern region.

\subsection{PG Fit}

PG fit increases engagement in CSM when the effects of PO and N-S fits are controlled. That is, unlike PO and $\mathrm{N}$-S fits which decrease CSM, employees who receive work-related support from coworkers are more engaged in CSM and have stronger protean orientation than those with less supportive coworkers. Also, PG fit has greater unique effect on the four strategy types than PO and N-S fits. These findings could be attributed to the following: first, drawing from the theory of "intelligent career" (Arthur et al., 1995), PG fit is not only a complementary fit but also a career competency, thus it is expected to encourage CSM. The role of "knowing whom" competency as an enabler of CSM and a requirement for "intelligent careers" is well established in the literature. Coworkers' support is crucially important for coping with the stresses of today's career demands because it provides members with direct technical and emotional career-related assistance, such as feedback, information and advocacy (Eby, Butts \& Lockwood, 2003; Ng et al., 2005). Second, it has been argued that since coworkers are rarely the cause of PO and N-S misfits, their support is often positive unlike the supervisors'. As mentioned before, supervisors might be considered as part of the misfit problem hence their support might be perceived as false (Mayo, 2012). Third, the findings are also consistent with organizational behavior research which indicates that members of cohesive workgroups seek consensual validation of their personal actions and beliefs from their groups, and seek the group's support and backing, and hence feel more empowered to take proactive actions (Adkins \& Meglino, 1996; $\mathrm{Ng}$ et al., 2005). Fourth, coworker support might be more needed and effectual in the Arab region because of the high power-distance, collectivistic and low agency culture, as well as the Arab's strong tendency for risk aversion.

It is worth noting that PG fit is a relatively new construct and when conceptualized in terms of values congruence and not team support, it produces weak and inconsistent relations with individual attitudes and behavior (Greguras \& Diefendorff, 2009). This led these authors and others to call for more research to explore the different conceptualizations of this construct. In response, this study examined the impact of PG fit on CSM and found a strong relationship between the two constructs. We surmise that the robust effects of PG fit in this study may relate to the construct's emphasis on support received by the employees from coworkers and not the congruence of their values. In support, Cable and DeRue (2002) found that competence-based fit and complementary fit (i.e., fulfilling needs through support) are more effective behavior antecedents than supplementary fit (values congruence). Further, the robust effect of PG fit on CSM may also be attributed to Arabs' strong in-group collectivistic culture, whereby people define career success in social terms, such as acceptance by the in-group and social standing (Abdalla and Al-Homoud, 2012). Given the Arabs' traditional culture, we surmise that those with in-group support and "knowing whom" career competency will have a stronger sense of control and empowerment (Inkson \& Arthur, 2001), and hence feel more encouraged to engage in CSM.

Taken together, the results support previous findings and extend P-E fit and CSM theories to the Arab region. They suggest that employees deploy a wide variety of tactics to fit in so as to enhance their careers. They are more energized to use these tactics when they have supportive workgroups, when their needs are not met by the job and when their personal values are incongruent with their organization's values. From this perspective the results confirm the assertions that N-S, PG and PO fit are important to employees' career advancement and operate through processes that are separate and distinct (Cable \& Edwards, 2004). The differential effects of the different types of fit on CSM revealed by this study suggest that the seemingly inconsistent findings concerning contextual effects on CSM reported by previous research (e.g., Hirschi et al, 2013) may relate to differences in the types of contextual factors used in those studies.

\section{Conclusions, Practical Implications and Limitations}

P-E fit needs to be adequately understood within career development research (Parker \& Collins, 2010; Halbesleben, 2010) to advance formal knowledge and form more effective socio-economic settings that optimize employees' career development, performance and wellbeing. While existing CSM studies have primarily attempted to isolate socio-economic factors, which predict employees' proactive career behavior, this analysis extended CSM research base by employing a P-E fit theoretical framework, frequently used to predict employees' attitudes and behavior, but very rarely seen in CSM research. Specifically, we explored three types of 
P-E fit namely, PO, PG and N-S fits, that might foster or undermine employees' engagement in CSM in the low agency and traditional, Kuwaiti context. We sought to contribute to the emerging research assessing how unique is the contributions of different types of fit on employees' attitudes and behaviors as well as to bridge P-E fit, career and organizational support literature. The analysis incorporated multiple measures of fit simultaneously, a strategy that has been recommended by some industrial and organizational psychology researchers, but not common in fit research (Kristof- Brown, Jansen, \& Colbert, 2002; Tak, 2011).

Taking the findings of the current study in total, it was evident that fit matters in the emergence of self-directed career management of young highly educated employees in Kuwait. The relations between fit and CSM were found to be consistent with previous Western-based data (Kristof-Brown et al., 2002). These findings demonstrate that PO, PG and N-S fit can have simultaneous and independent effects on CSM, and that the intensity and direction of the effects may differ depending on the type of fit. They substantiate previous research which found that employees distinguish between PO, PG and N-S fit perception and that incongruencies between the employees' values and needs and what their organizations offer motivate protean career behavior. Research that clarifies the complexities through which P-E fit influences career proactive behavior will continue to inform the theory and practice about the role that fit plays in employees' and organizations' prosperity.

The most straightforward implication of the present findings is that managers should be aware of the divergent effects of different kinds of fit on employees' career behavior, particularly those that increase employees' stressors, like the incongruence between employees and their organizations in terms of value-systems, needs and supplies. Eliminating such incongruence may lessen the CSM burdens shouldered by today's employees. To increase P-E fit, managers may find it particularly valuable to develop organizational "standards of fit" and compare their performance relative to other firms or industry benchmarks. Such information is essential for HRM decisions and is helpful to employees and counselors involved in CSM and career development. The main limitations of this study are that it is cross-sectional and applied only self-report methods. However, the high validity and reliability of the constructs support the value and contributions of the study.

\section{Acknowledgement}

This study was partially funded by Kuwait Foundation for the Advancement of Science, Kuwait.

\section{References}

Abdalla, I. (2006). Human resource management in Qatar, in P. S. Budhwar, and K. Mellahi, (Eds.). Managing Human Resources in the Middle East, (pp. 121-144). Global HRM Research Monograph Series, London, England, Routledge.

Abdalla, I. A., Al Homoud, M. A., \& Muhammad, A. H. (2019). Demographic Differences in Protean Career Behavior: A Study of a High Demographic Inequality Labor Market. International Journal of Business and Management, 14(8), 25-40. https://doi.org/10.5539/ijbm.v14n8p25

Abdalla, I., \& Al-Homoud, M. (2012). Foreign faces in Kuwaiti places: the challenges of human capital utilization in Kuwait. International Journal of Business and Management, 7(2), 1-12. https://doi.org/10.5539/ijbm.v7n20p1

Adkins, C. L., \& Meglino, B. M. (1996). Value congruence between coworkers and its relationship to work outcomes. Group and Organization Management, 21, 439-460. https://doi.org/10.1177/1059601196214005

Arthur, M. B., \& Rousseau D. M. (1996). Introduction: the boundaryless career as a new employment principle, in Arthur, M. B., and Rousseau D. M. (Eds.), The boundaryless career. New York, Oxford University Press, 3-20.

Arthur, M. B., Claman, P. H., \& DeFillippi, R. J. (1995). Intelligent enterprise, intelligent careers, The Academy of Management Executive, 9(4), 7-20. https://doi.org/10.5465/ame.1995.9512032185

Arthur, M. B., Inkson, K., \& Pringle, J. K. (1999). The New Careers, Sage, London, Pages (1999).

Ashford, S. J., \& Black, J. S. (1996). Proactivity during organizational entry: the role of desire for control. Journal of Applied Psychology, 81, 199-214. https://doi.org/10.1037/0021-9010.81.2.199

Baruch, Y. (2014). The development and validation of a measure for protean career orientation. The International Journal of Human Resource Management, 25(19), 2702-2723. https://doi.org/10.1080/09585192.2014.896389

Briscoe, J. P., \& Hall, D. T. (2006). The interplay of boundaryless and boundaryless careers combinations and implications. Journal of Vocational Behavior, 69, 4-18.https://doi.org/10.1016/j.jvb.2005.09.003 
Briscoe, J. P., Henagan, S. C., Burton, J. P., \& Murphy, W. M. (2012). Coping with an insecure employment environment: the differing roles of protean and boundaryless career orientations. Journal of Vocational Behavior, 80, 308-316. https://doi.org/10.1016/j.jvb.2011.12.008

Brislin, R. W. (1970). Back-translation for cross-cultural research. Journal of Cross-Cultural Psychology, 1(3), 185-216. https://doi.org/10.1177/135910457000100301

Cable, D. M., \& Edwards, J. R. (2004). Complementary and supplementary fit: a theoretical and empirical integration. Journal of Applied Psychology, 89(5), 822-834. https://doi.org/10.1037/0021-9010.89.5.822

Cable, D., \& DeRue, D. (2002). The convergent and discriminant validity of subjective fit perceptions. Journal of Applied Psychology, 87(5), 875-884.

Cao, L., Hirschi, A., \& Deller, J. (2012). Self-initiated expatriates and their career success. Journal of Management Development, 31(2), 159-172. https://doi.org/10.1108/02621711211199494

Carter, N., \& Silva, C, (2011). The Myth of the Ideal Worker: Does doing all the right things get women ahead? Catalyst Publication, New York, NY.

Crawshaw, J. R., Dick, V. R., \& Brodbeck, F. C. (2012). Opportunity, fair process and relationship value: career development as a driver of proactive work behavior. Human Resource Management Journal, 22(1), 4-20. https://doi.org/10.1111/j.1748-8583.2011.00169.x

De Vos, A., \& Soens, N. (2008). Protean Attitude and Career success: The mediating role of self-management, Journal of Vocational Behavior, 73, 449-456. https://doi.org/10.1016/j.jvb.2008.08.007

Direnzo, M. S., \& Greenhaus, J. (2011). Job search and voluntary turnover in a boundaryless world: a Control Theory perspective. Academy of Management Review, 36(3), 567-589. https://doi.org/10.5465/amr.2009.0333

Eby, L. T., Butts, M., \& Lockwood, A. (2003). Predictors of success in the era of the boundaryless career. Journal of Organizational Behavior, 24(6), 689-708. https://doi.org/10.1002/job.214

Edwards, J. R. (1991). Person-job fit: A conceptual integration, literature review, and methodological critique. In C. L. Cooper \& I. T. Robertson (Eds.), International Review of Industrial and Organizational Psychology, 6, 283-357. Oxford, England: John Wiley \& Sons.

Greguras, G. J. J., \& Diefendorff, J. M. (2009). Different fits satisfy different needs: Linking person-environment fit to employee commitment and performance using self-determination theory. Journal of Applied Psychology, 94(2), 465-477. https://doi.org/10.1037/a0014068

Gubler, M., Arnold, J., \& Coombs, C. (2014). Organizational boundaries and beyond: a new look at the components of boundaryless career orientation. Career Development International, 19(6), 641-667. https://doi.org/10.1108/CDI-11-2013-0143

Hair, J. F., Black, W. C., Babin, B. J., Anderson, R. E., \& Tatham, R. L. (2006). Multivariate Data Analysis, 6th ed., NJ, Pearson Education Inc.

Halbesleben, J. R. (2010). Sources of social support and burnout: a meta-analytic test of conservation of resources model. Journal of Applied Psychology, 91, 1134-1145. https://doi.org/10.1037/0021-9010.91.5.1134

Hertog, S. (2012). A comparative assessment of labor market nationalization policies in the GCC, in Hertog, S. (ed.), National employment, migration and education in the GCC. The Gulf Region: economic development and diversification, Gerlach Press, Berlin, Germany.

Hirschi, A., Lee, B., Porfeli, E., \& Vondracek (2013). Proactive motivation and engagement in career behaviors: Investigating direct, mediated, and moderated effects. Journal of Vocational Behavior, 83(1), 31-40. https://doi.org/10.1016/j.jvb.2013.02.003

Hofstede, G. (2001). Culture's Consequences: comparing values, behaviors, institutions, and organizations across nations (2nd ed.), CA, Sage.

Inkson, K., \& Arthur, M. B. (2001). How to be a successful career capitalist. Organizational Dynamics, 30(1), 48-61. https://doi.org/10.1016/S0090-2616(01)00040-7

Inkson, K., \& King, Z. (2011). Contested terrain in careers: A psychological contract model. Human Relations, 64(1), 37-57. https://doi.org/10.1177/0018726710384289

Kahn, W. A. (1990). Psychological conditions of personnel engagement and disengagement at work. Academy of Management Journal, 33(4), 692-724. https://doi.org/10.5465/256287 
King, Z. (2001). Career self-management: a framework for guidance of employed adults. British Journal of Guidance and Counselling, 29(1), 65-78. https://doi.org/10.1080/03069880020019365

Kostal, J. W., \& Wiernik, B. M. (2017). A meta-analytic investigation of demographic differences in protean, boundaryless, and proactive career orientations. Career Development International, 22(5), 520-545. https://doi.org/10.1108/CDI-08-2017-0139

Kristof, A. L. (1996). Person-organization fit: an integrative review of its conceptualizations, measurement, and implications. Personnel Psychology, 49, 1-49. https://doi.org/10.1111/j.1744-6570.1996.tb01790.x

Kristof-Brown, A. L., Jansen, K. J., \& Colbert, A. E. (2002). A policy-capturing study of the simultaneous effects of fit with jobs, groups, and organizations. Journal of Applied Psychology, 87(5), 985-993. https://doi.org/10.1037/0021-9010.87.5.985

Kristof-Brown, A. L., Zimmerman, R. D., \& Johnson, E. C. (2005). Consequences of individuals' fit at work: a meta-analysis of person-job, person-organization, person-group, person-supervisor fit. Personnel Psychology, 58, 281-342. https://doi.org/10.1111/j.1744-6570.2005.00672.x

Lent, R., \& Brown, S. (2013). Social cognitive model of career self-management: towards a unifying view of adaptive career behavior across the life span. Journal of Counseling Psychology, 60(4), 557-568. https://doi.org/10.1037/a0033446

Locke, E. (2000). Motivation, cognition, and action: an analysis of studies of task goals and knowledge. Journal of Applied Psychology, 49(3), 408-429. https://doi.org/10.1111/1464-0597.00023

Mayo, M., Sanchez, J. I., Pastor, J. C., \& Rodriguez, A. (2012). Supervisor and coworker support: a source congruence approach to buffering role conflict and physical stressors. The International Journal of Human Resource Management, 23(18), 3872-3889. https://doi.org/10.1080/09585192.2012.676930

McEvoy, G., \& Buller, P. F. (2013). Research for practice: The management of expatriates. Thunderbird International Business Review, 55(2), 213-226. https://doi.org/10.1002/tie.21536

Ng, T. W., Eby, L. T., Sorensen, K. L., \& Feldman, D. C. (2005). Predictors of objective and subjective career success: a meta-analysis. Personnel Psychology, 58(2), 367-408. https://doi.org/10.1111/j.1744-6570.2005.00515.x

Ng, T., Sorensen, K., Eby, T., \& Feldman, D. (2007). Determinants of job mobility: a theoretical integration and extension. Journal of Occupational and Organizational Psychology, 80, 363-386. https://doi.org/10.1348/096317906X130582

Parker, S. K., \& Collins, C. G. (2010). Taking Stock: integrating and differentiating multiple proactive behaviors. Journal of Management, 36(3), 633-662. https://doi.org/10.1177/0149206308321554

Parker, S., Bindle, U., \& Straus, K. (2010). Making things happen: a model of proactive motivation. Journal of Management, 20(10), 827-856. https://doi.org/10.1177/0149206310363732

Rousseau, D. M. (1998). The 'problem' of the psychological contract considered". The Journal of Organizational Behavior, 19(S1), 665-671. https://doi.org/10.1002/(SICI)1099-1379(1998)19:1+<665::AID-JOB972>3.0.CO;2-X

Ryan, R. M., \& Deci, E. L. (2000). Self-determination theory and the facilitation of intrinsic motivation, social development and wellbeing. American Psychologist, 55, 68-78. https://doi.org/10.1037/0003-066X.55.1.68

Schneider, B. (1987). The people make the place. Personnel Psychology, 40, 437-453. https://doi.org/10.1111/j.1744-6570.1987.tb00609.x

Schwartz, S. H. (1992). Universals in the content and structure of values: Theoretical advances and empirical tests in 20 countries. Advances in Experimental Social Psychology, 25, 1-65. https://doi.org/10.1016/S0065-2601(08)60281-6

Segers, J., Inceoglu, I., Vloeberghs, D., Bartram, D., \& Henderickx, E. (2008). Protean and boundaryless careers: a study on potential motivators. Journal of Vocational Behavior, 73, 212-230. https://doi.org/10.1016/j.jvb.2008.05.001

Seibert, S. E., Kraimer, M. L., \& Crant, J. M. (2001). What do proactive people do? A longitudinal model linking proactive personality and career success. Personnel Psychology, 54(4), 845-874. https://doi.org/10.1111/j.1744-6570.2001.tb00234.x

Seong, J. Y., \& Kristof-Brown, A. L. (2012). Testing multidimensional models of person-group fit. Journal of 
Managerial Psychology, 27(6), 536-556. https://doi.org/10.1108/02683941211252419

Tak, J. (2011). Relationships between various person-environment fit types and employee withdrawal behavior: A longitudinal study. Journal of Vocational Behavior, 78(2), 315-320.

https://doi.org/10.1016/j.jvb.2010.11.006

Wang, Q., Weng, Q, McElroy, J. C., Ashkanasy, N. M., \& Lievens, F. (2014). Organizational career growth and subsequent voice behavior: The role of affective commitment and gender. Journal of Vocational Behavior, 84, 431-441. https://doi.org/10.1016/j.jvb.2014.03.004

Werbel, J. D., \& Gilliland, S. W. (1999). Person-environment fit in the selection process. In Ferris G. R. (Ed.), Research in Personnel and Human Resource Management, 17, (pp. 209-243). Stanford, CT: JAI Press.

\section{Copyrights}

Copyright for this article is retained by the author(s), with first publication rights granted to the journal.

This is an open-access article distributed under the terms and conditions of the Creative Commons Attribution license (http://creativecommons.org/licenses/by/4.0/). 